\title{
Effects of Elevated Temperatures on Mechanical's concrete specimen behaviour
}

\author{
Nesrine Khodja ${ }^{1, *}$, and Hadda Hadjab $^{2}$ \\ ${ }^{1} \mathrm{PhD}$ student, University of science and Technology Houari Boumediene16111 Bab Ezzouar Alger, Algiers \\ ${ }^{2}$ Professor, University of Science and Technology Houari Boumediene16111 Bab Ezzouar Alger, Algiers
}

\begin{abstract}
This paper presents an experimental study on the performance of concrete, subjected to high temperatures. Investigation was carried out by using two mixtures: an Ordinary Concrete (OC) and High Performance Concrete (HPC) with $10 \%$ of Silica Fume (SF) replaced of cement weight and 1,5\% of super plasticizer, the water-binder $(\mathrm{w} / \mathrm{b})$ ratio used was 0,5 and 0,32 respectively. The produced concrete specimens are heated at a rate of $7{ }^{\circ} \mathrm{C} / \mathrm{min}$ up to different temperatures $\left(150,300,450,600\right.$ and $\left.900^{\circ} \mathrm{C}\right)$. In order to ensure a uniform temperature through the specimen, the temperature is held constant at the temperature stage for one hour before cooling. Mechanical properties at ambient temperature and residual mechanical properties after heating have already been determined. We examined also the effect of high temperature on the aggregate-cement paste interface and aggregate microstructure of the concrete specimens by scanning electron microscopy (SEM) method to reveal changes occurred after the cycle of heatingcooling. The results revealed that relative strength of the concrete specimens decreased as the exposure temperature increased and reaches about a quarter of its initial strength at $900^{\circ} \mathrm{C}$. Moreover SEM examinations showed that, increasing temperature caused weakening of the adherence of aggregate and cement matrix by the appearance of cracks and micro cracks.
\end{abstract}

\section{Introduction}

At high temperatures or under thermal situations such as fire in tunnels (Channel, Mont Blanc, Great Belt Link, Tauern) and nuclear reactors, prediction of concrete performances is of great importance for safety evaluation of concrete structures. HPC is considered as a revolutionary material but its behavior is not yet mastered when exposed to high temperatures. Under these conditions, physical and chemical changes in the microstructure of concrete affect widely its mechanical behavior. Furthermore knowledge of the microscopic behavior of high temperature concretes is interesting to demonstrate the physico-chemical transformation and observe the influence of the different constituents of the concrete. Dehydration of the matrix components from $110^{\circ} \mathrm{C}$ to about $550^{\circ} \mathrm{C}$ causes shrinkage and thus cracking of the concrete $[1,2,3,4]$. Similarly aggregates undergo changes following a high temperature rise, such as the decarbonation of calcareous aggregates at about $800^{\circ} \mathrm{C}-900^{\circ} \mathrm{C}[4,5,6]$. The aim of this work was to study the effect of high temperatures (ranging from $20^{\circ} \mathrm{C}$ to $900^{\circ} \mathrm{C}$ ) on the compressive strength of a high performance concrete comparing with a reference concrete, in addition to microstructural observations who allowed showing on a very good scale the appearance of cracks in the cement paste and around the aggregates.

\section{Materials and Testing}

The cement used in the present study was Portland cement (CEM II/B 42.5) with specific weight 3.15 and the specific surface area of PC measured with Blaine method was $4235 \mathrm{~cm}^{2} / \mathrm{g}$. Two types of sand are used,
(S1) fine sand (0/1), with a modulus of fineness $\mathrm{Mf}=$ 0.97 with specific gravity 2.58 , made it possible to carry out the correction of the granulometry of (S2) the coarse sand $(0 / 4)$ of $\mathrm{Mf}=3.1$ with specific gravity 2.66, Making it possible to obtain a sand mixture of $\mathrm{Mf}=2.5$ and having a granulometric curve lying inside the normalized zone. One type of coarse aggregate was employed to carry out this research, Silicate-limestone aggregate $(\mathrm{G})$ with specific gravity 2.71 , the considered silica fume (SF) used contains a silica of $95 \%$ with a specific weigh 2.2. The superplasticizer used was incorporated in the concrete mixture to improve workability. The specific weight of super plasticizer was $1.07 \mathrm{~g} / \mathrm{cm}^{3}$.

The distribution of coarse aggregate (gravel) in comparison with the sand aggregate are shown in (Fig.1), Tap water at room temperature was used in all mixes.

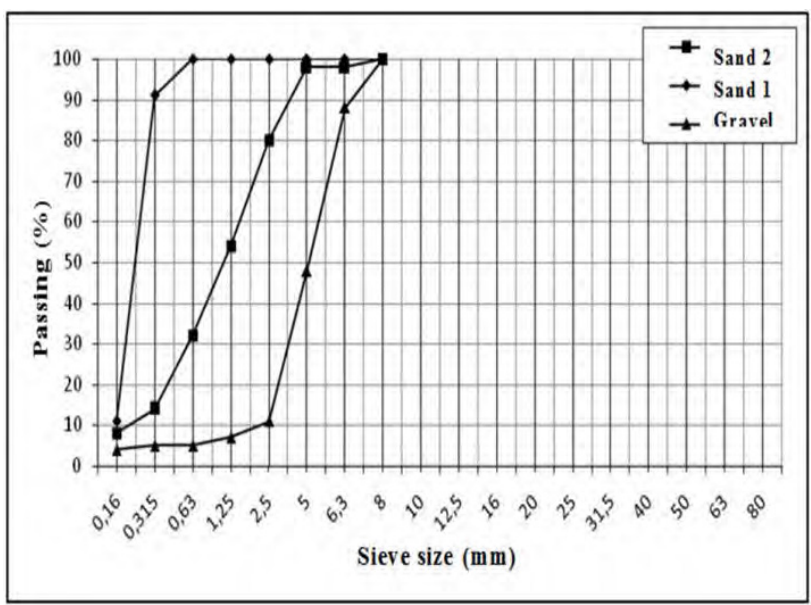

Fig. 1. Sieve analyses of aggregates.

Corresponding author: khodja.nesrine@gmail.com 


\subsection{Mix proportion}

In this study two groups of concrete mixtures were used. In group 1, Ordinary concrete (OC) was formulated according to Dreux-Gorisse method, the water-cement $(w / c)$ ratio used in mixture was 0.5 . On the other hand, group 2, mixture design was made with according to the formulation method of the University of Sherbrook, which makes it possible to formulate (HPC) without air entrained according to the standard ACI 211-1[7]. The water-binder $(\mathrm{w} / \mathrm{b})$ ratio used in mixture was 0.32 . SF was used at $10 \%$ replacement by weight of cement. The proportions of concrete mixes are given in Table 1, Table 2 respectively.

Table 1. Composition of Ordinary concrete $(\mathrm{kg} / \mathrm{m} 3)$.

\begin{tabular}{|c|c|c|c|c|}
\hline component & $\mathbf{( \% )}$ & Density & Volume (l) & weight (Kg) \\
\hline Sand S1 & $10 \%$ & 2,58 & 63,6 & 164 \\
\hline Sand S2 & $25 \%$ & 2,66 & 163,54 & 435 \\
\hline Gravel & $65 \%$ & 2,72 & 421,83 & 1147 \\
\hline cement & - & 3,1 & 129,03 & 400 \\
\hline Water & - & 1 & 208 & 208 \\
\hline
\end{tabular}

Table 2. Composition of High Performance concrete (kg/m3).

\begin{tabular}{|c|c|c|c|c|c|}
\hline \multicolumn{2}{|c|}{ component } & $(\%)$ & Density & $\begin{array}{l}\text { Volume } \\
\text { (I) }\end{array}$ & $\begin{array}{c}\text { weight } \\
\text { (Kg) }\end{array}$ \\
\hline \multicolumn{2}{|c|}{ Sand S1 } & $11 \%$ & 2,58 & 88,9 & 229 \\
\hline \multicolumn{2}{|c|}{ Sand S2 } & $29 \%$ & 2,66 & 228,6 & 608 \\
\hline \multicolumn{2}{|c|}{ Gravel } & $60 \%$ & 2,72 & 476,25 & 1295 \\
\hline $\begin{array}{c}\text { équivalent } \\
\text { binder }\end{array}$ & $\mathrm{C}$ & $90 \%$ & 3,1 & 145,16 & 450 \\
\hline $\begin{array}{c}\mathrm{b}= \\
\mathrm{C}+2 \mathrm{SF}\end{array}$ & SF & $10 \%$ & 2,2 & 11,36 & 50 \\
\hline \multicolumn{2}{|c|}{ Water } & $5.8 \%$ & 1 & 161,28 & 161 \\
\hline \multicolumn{2}{|c|}{$\begin{array}{l}\text { Superplasticizer } \\
(1.5 \% \text { of } b)\end{array}$} & $1.5 \%$ & 1,07 & 2,26 & 7,5 \\
\hline
\end{tabular}

\subsection{Test procedure}

Parallelepipedic specimens $(4 \times 4 \times 16 \mathrm{~cm})$ were prepared then cured in lime saturated water at $20 \pm 2{ }^{\circ} \mathrm{C}$ until the time of the testing. After 28 days the specimens of concrete were placed in an electric oven for performing the fire tests (maximum temperature of $1200{ }^{\circ} \mathrm{C}$ ). The used furnace (PROETI HD-230) could achieve a high heating rate speed that is somewhat similar to actual fire conditions. The dimensions of the oven hole are of 200 $\mathrm{mm} \cdot 200 \mathrm{~mm} \cdot 200 \mathrm{~mm}$, provided with insulator material and the outer body is stiff steel, to safeguard the user in the case of concrete specimen explosion. Specimens are heated to desired temperature of 150, 300, 450,600 and $900^{\circ} \mathrm{C}$ (Figure. 2). The heating rate was set at $7^{\circ} \mathrm{C} / \mathrm{min}$ for all cases, which is consistent with RILEM 129-MHT standard recommendation $[8,9]$ and In order to ensure a uniform temperature through the specimen, this last is held constant at the temperature stage for one hour before cooling to room temperature at the air (Figure. 3).

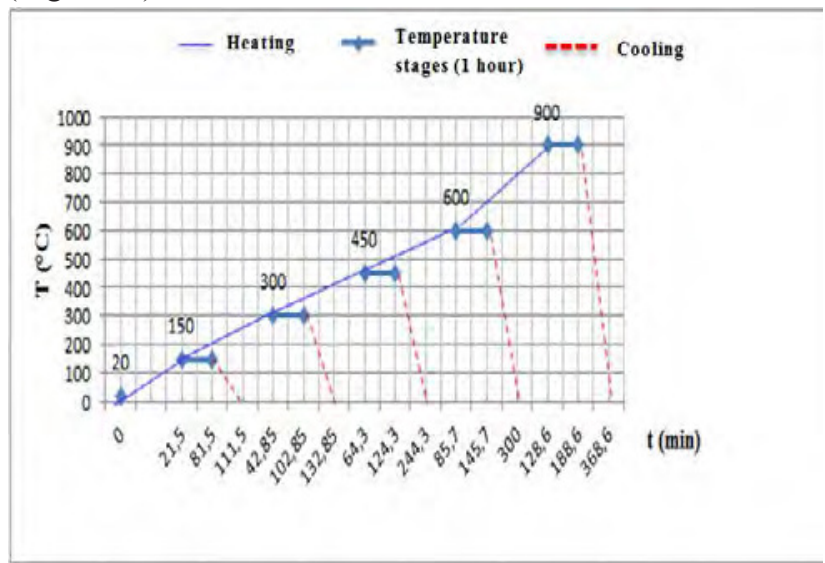

Fig. 2. Heating and cooling cycle.
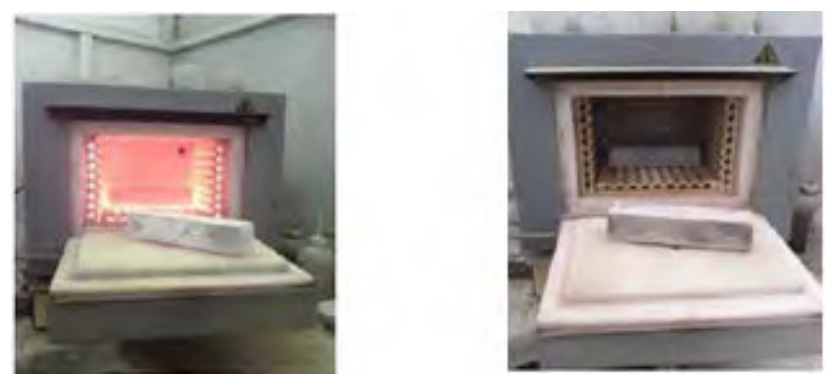

Fig. 3. Cooling the test specimens in air.

The compressive strength of concrete specimens was measured owing to uniaxial compression instrument (Figure.4) with a capacity of $3000 \mathrm{kN}$ and loading rate was $0.5 \mathrm{MPa} / \mathrm{s}$. The compressive strength tests were carried out on the specimens after exposed to elevated temperatures. Three specimens were used for each temperature and each cooling regimes to perform compressive strength tests. And the average of three measurements of specimens was presented and discussed in the study.
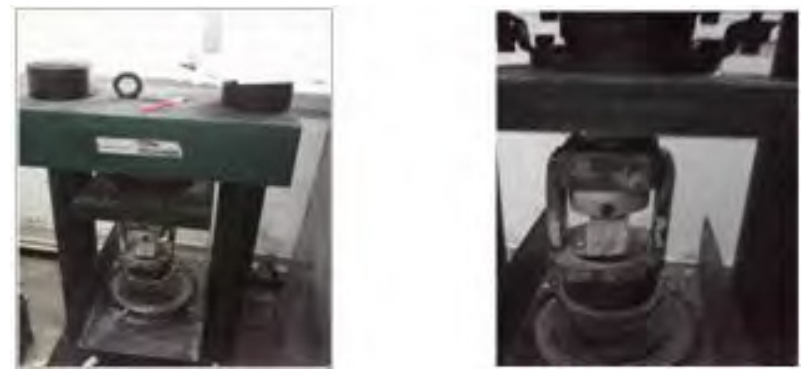

Fig. 4. Compressing test on prismatic specimen.

After strength testing, the samples were collected and marked in air tight containers to undergo Scanning Electron Microscopy (SEM) for changes to their microstructure. In this work, microstructural examinations and analyzes were carried out using the Scanning Electron Microscope (SEM - QUANTA 600). The device is equipped with an EDS microanalyzer and can work under conditions of environmental pressure. Figure.5 gives an overview of this installation. 
The microstructural analysis was carried out at welldefined temperatures, namely: $20^{\circ} \mathrm{C}, 300^{\circ} \mathrm{C}$ and $600^{\circ} \mathrm{C}$. The samples heated to $900^{\circ} \mathrm{C}$. were severely damaged by the heat shock resulting from air cooling so that these samples were not subjected to microstructural analysis therefore it was impossible to characterize the cracking.

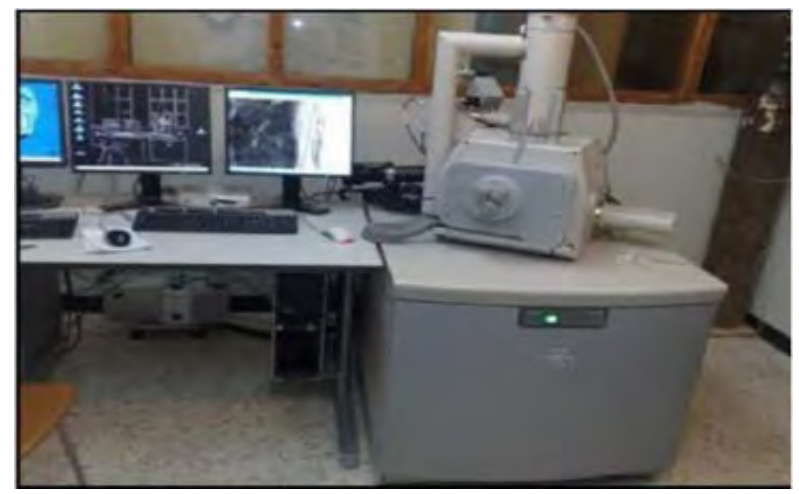

Fig. 5. Scanning Electron Microscope QUANTA 600.

\section{Results and discussion}

\subsection{Residual compressive strength}

The concrete specimens produced in this study were exposed to the elevated temperatures at 150, 300, 450, 600 and $900^{\circ} \mathrm{C}$, then their residual compressive strength values were determined. The residual compressive strengths of concrete specimens are presented in (Fig.6), for ordinary and high performance concrete successively. The residual compressive strength ratios at elevated temperatures as compared to the original strength before heating $\left(20^{\circ} \mathrm{C}\right)$ are given in (Fig. 7$)$.

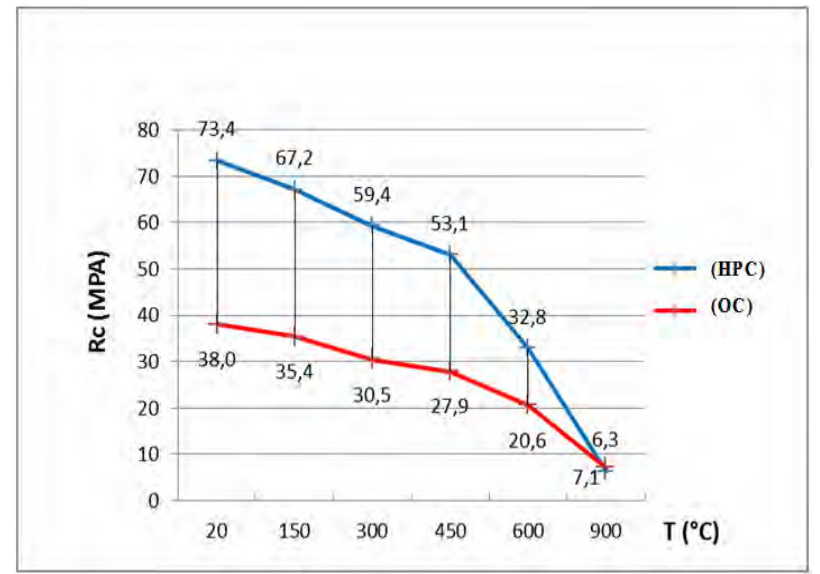

Fig. 6. Residual compressive strengths with increasing temperature

There are two concrete behavior zones. In the first zone, which varies from room temperature to $450^{\circ} \mathrm{C}$, there is a decrease in resistance but in all cases of small magnitude. In the second zone starting from the intermediate limit to $900{ }^{\circ} \mathrm{C}$, there is a continual decrease in the compressive strength and this regardless of the type of concrete.
It was seen from (Fig.6) that the compressive strength value of high performance concrete decreases significantly with increasing temperature passing from 73.44 MPA at $20^{\circ} \mathrm{C}$ until reaching an ultimate value of 6.3 MPA at $900^{\circ} \mathrm{C}$. It exhibited approximately $91 \%$ of the strength value which was measured at room temperature. In comparison with normal concrete who loses about $81 \%$ of its initial resistance. As reported in the literature $[10,11]$. This decrease in compressive strength may be the occurrence of micro and macrocracks in concrete because of thermal stress formations resulting from the temperature differences between surface and core high temperature [12].

At $150{ }^{\circ} \mathrm{C}$, (HPC) and (OC) mixture was not affected significantly (Fig.7). It exhibited approximately $91.5 \%$ and $93 \%$ respectively of the strength value which was measured at room temperature. Referring to [14] the decrease in resistance is due to an increase in the chemical energy of the water, which, by increasing the number of layers adsorbed on the surface of the solids, increases the disjunction pressures between the Different CSH layers.

When the temperature reached to $450{ }^{\circ} \mathrm{C}$, the compressive strength of specimens decreased between $20 \%$ and $27.65 \%$. This temperature is critical because calcium hydroxide dehydration takes place about $550{ }^{\circ} \mathrm{C}$ [14]. In addition, this result causes the shrinkage and strength loses of concrete [15].

The strength losses $(41.81 \%, 55.3 \%$ respectively) which were occurred in the ordinary and high concrete specimens respectively increased significantly when the temperatures were reached to 600 and $900^{\circ} \mathrm{C}$ due to the decomposition of $\mathrm{C}-\mathrm{S}-\mathrm{H}$ gel $[15,16]$. The concrete specimens were completely disintegrated at $900{ }^{\circ} \mathrm{C}$.

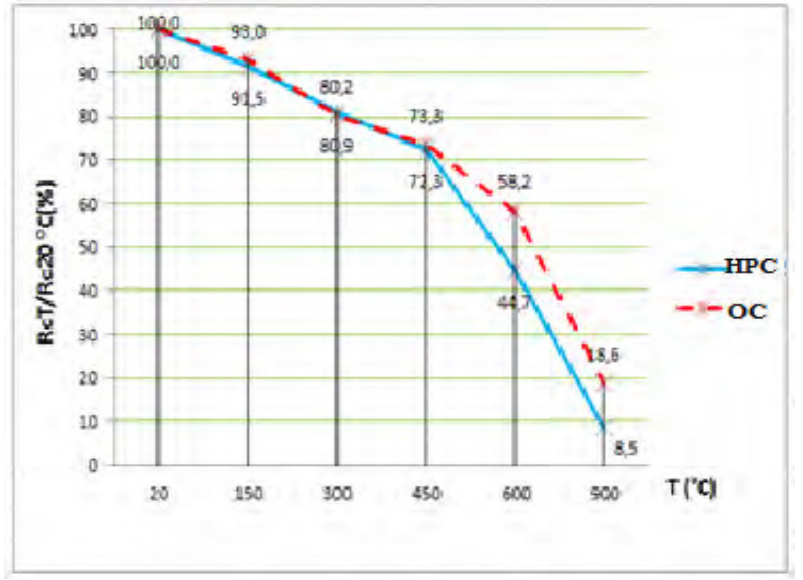

Fig. 7. Relative compressive strengths with increasing temperature

One possible explanation of this reduction in strength may be the incompatibilities between the different phases of concrete (matrix and aggregates). During cooling the stresses caused by the thermal incompatibilities of these materials induce cracking resulting in lower strengths [13]. 


\subsection{Scanning Electron Microscopy (SEM)}

\subsubsection{At $20^{\circ} \mathrm{C}$}

Scanning Electron Microscopy (SEM) was used to obtain micrographs of (HPC) and (OC) samples before heating (at $20^{\circ} \mathrm{C}$ ) and after exposure to high temperatures $\left(300^{\circ} \mathrm{C}\right.$ and $\left.600^{\circ} \mathrm{C}\right)$.

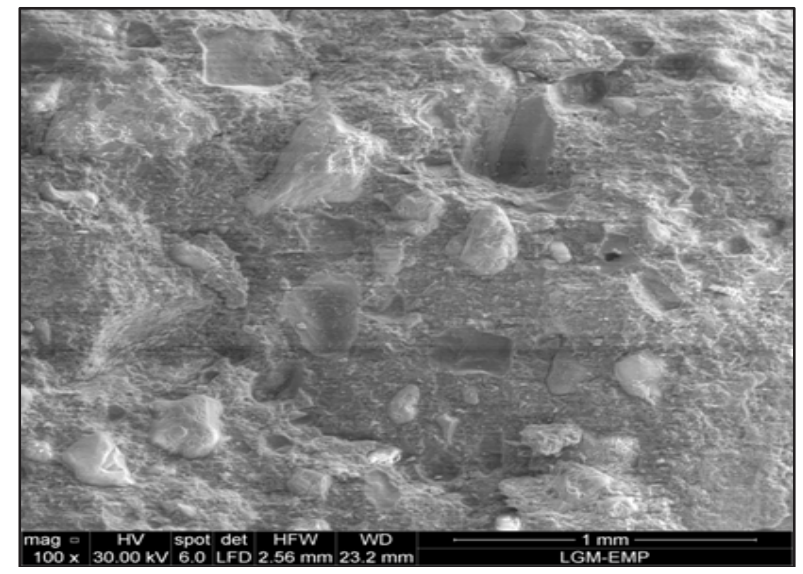

Fig. 8. SEM micrographs of OC sample at $20^{\circ} \mathrm{C}, 100 \mathrm{x}$.

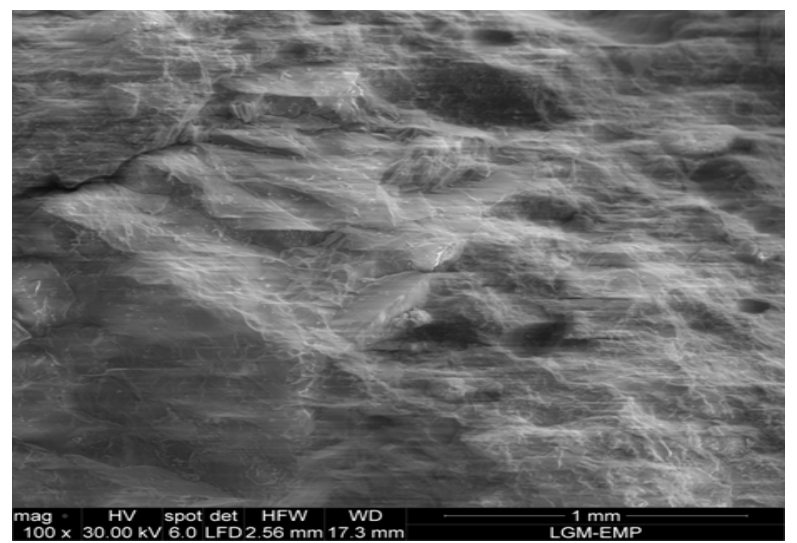

Fig. 9. SEM micrographs of HPC sample at $20^{\circ} \mathrm{C}, 100 \mathrm{x}$.

The surface of the ordinary concrete sample that has not been subjected to high temperatures (Fig.8) does not have any facies of alteration and no longer a particular crack. The dense and amorphous structure of (HPC) testifies that this material has not been thermally degraded.

Moreover, we note that the (OC) has a large number of pores or voids that can initially be air bubbles, characterized by black cavities as shown in the micrograph (Fig.8) thus generating a less dense area and more permeable. Unlike that of (HPC) which has an amorphous structure (Fig.9), and much less porous than conventional concrete.

For (HPC) at $20^{\circ} \mathrm{C}$ with an enlargement of $400 \mathrm{x}$. It is noted that there is a very good adhesion to the interface cement -granulate (Fig.11), it is almost perfect compared to that of ordinary concrete, as we can see the stripping (Fig.10) of materials due to the polishing operation, or evaporation of water, or air in the sample (OC). The exposed concrete in (Fig.11) containing silica fume has a stronger cohesion and is more compact compared to the $\mathrm{BO}$, the fineness of the silica fume particles allows them to fit between the grains of cement and at the paste aggregate interface by creating additional $\mathrm{CSH}$ due to the pozzolanic reaction with portlandite. As a result, a denser paste, a finer porosity and better adhesion with coarse aggregates result.

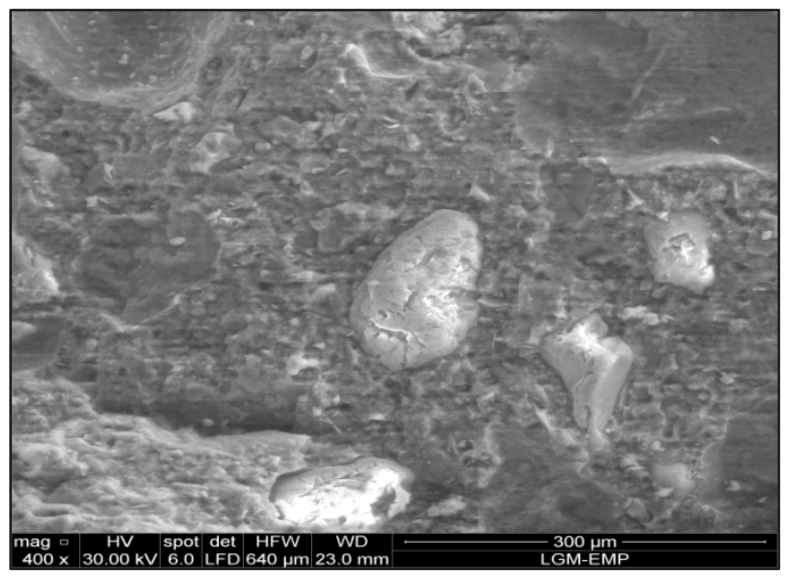

Fig. 10. SEM micrographs of OC sample at $20^{\circ} \mathrm{C}, 400 \mathrm{x}$.

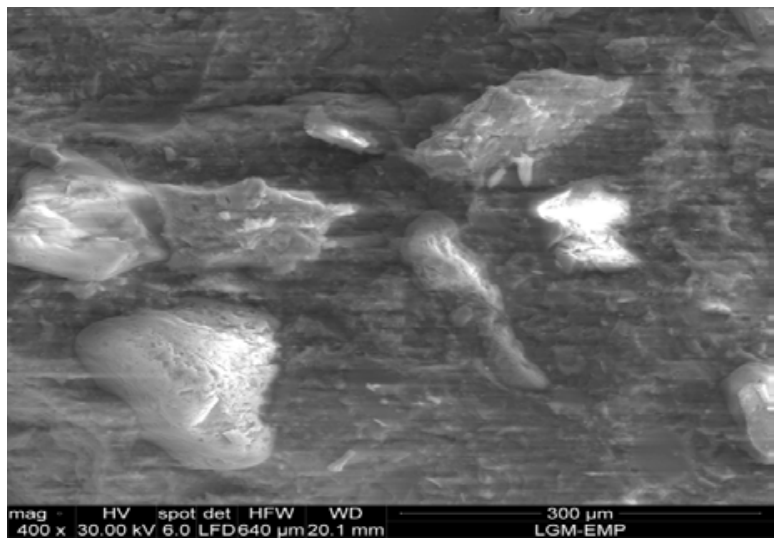

Fig. 11. SEM micrographs of $\mathrm{HPC}$ sample at $20^{\circ} \mathrm{C}, 400 \mathrm{x}$.

For (HPC), there is certain homogeneity between the grains of sand and the cement. In addition, the mineral Silica Fume (SF) leads to a densification of the microstructure, which has the effect of reducing the porosity of the transition halo. All these modifications improve the transfer properties and therefore the durability of (HPC).

\subsubsection{At $300^{\circ} \mathrm{C}$}

Aggregate surface texture is one of the most important factors affecting bond strength, for example rough surfaces usually have a higher bond than sawn surfaces. It is known that the transition zones (interfaces) are the weakest link of the concrete and crack growth usually starts at the aggregate-cement matrix interfaces [17].

In addition the adherence of aggregate and cement matrix of (OC) was observed as quite well (Fig.10). However, the adherence was not the same of specimen exposed to the temperature of $300^{\circ} \mathrm{C}$, capillary fissure 
which did not wraparound the aggregate completely was observed at the aggregate-cement matrix inter-faces of some aggregates (Fig.12).

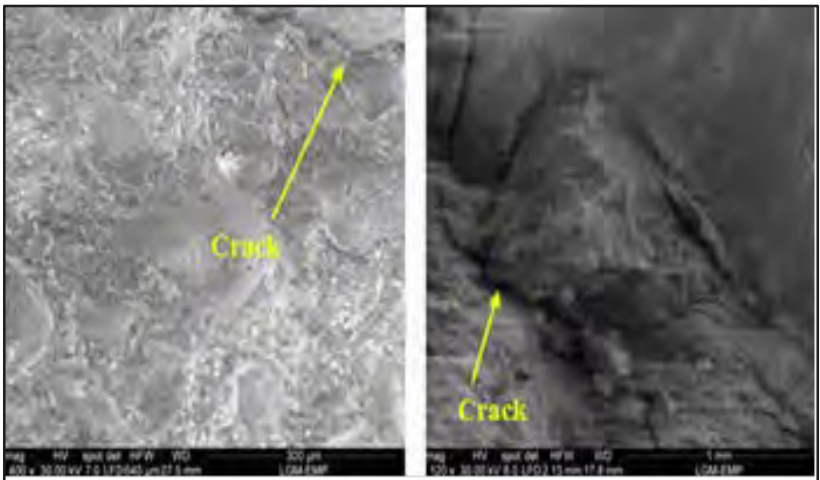

Fig. 12. SEM micrographs of $(\mathrm{OC})$ sample at $300^{\circ} \mathrm{C}, 400 \mathrm{x}$ (Intergranular cracks)

In high performance concrete cracks of different types are present. Trans-granular fissures passing through the aggregates (Fig.13, Fig 14) and inter-granular cracks (Fig.15), generally those of quartz nature. It is possible that these cracks are due to the phenomenon of cleavage which characterizes these aggregates at a temperature of $300^{\circ} \mathrm{C}$. In addition to the Intergranular cracks that protrude at the paste-aggregate interface (Fig.14).

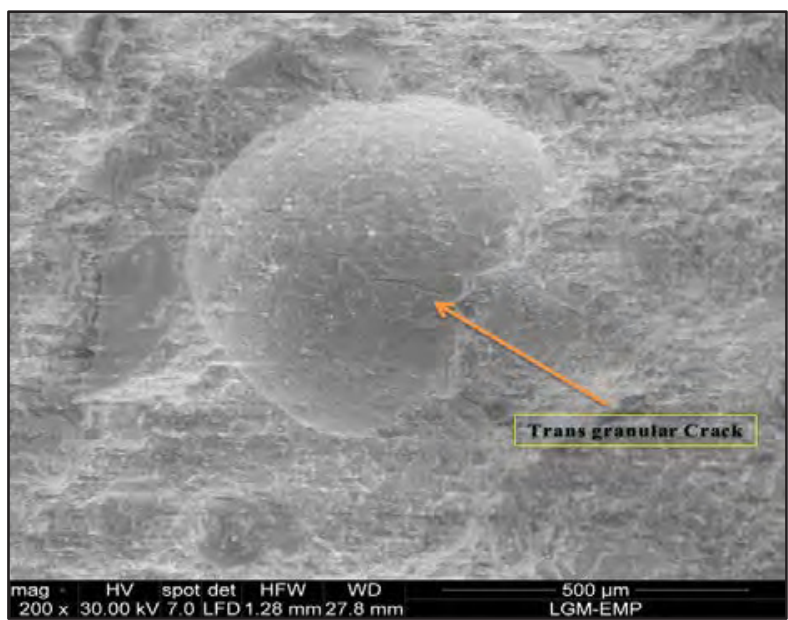

Fig. 13. SEM micrographs of (HPC) sample at $300^{\circ} \mathrm{C}, 200 \mathrm{x}$ (Transgranular cracks)

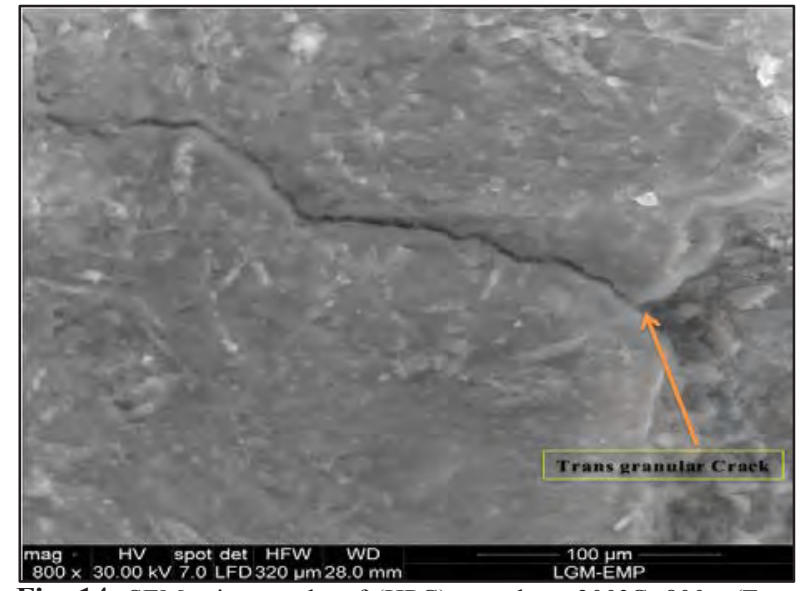

Fig. 14. SEM micrographs of (HPC) sample at $300^{\circ} \mathrm{C}, 800 \mathrm{x}$ (Transgranular cracks)

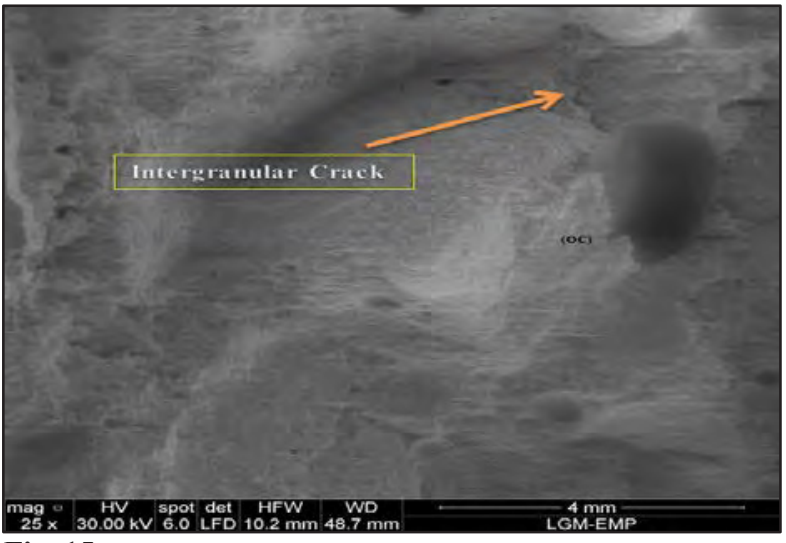

Fig. 15. SEM micrographs of (HPC) sample at $300^{\circ} \mathrm{C}, 25 \mathrm{x}$.

According to (Fig.16), it is clear that the hydration products formed up to $300^{\circ} \mathrm{C}, \mathrm{CSH}$; have a massive structure. And the porosity of the HPC remains relatively low as the microstructure of the latter is not so damaged.

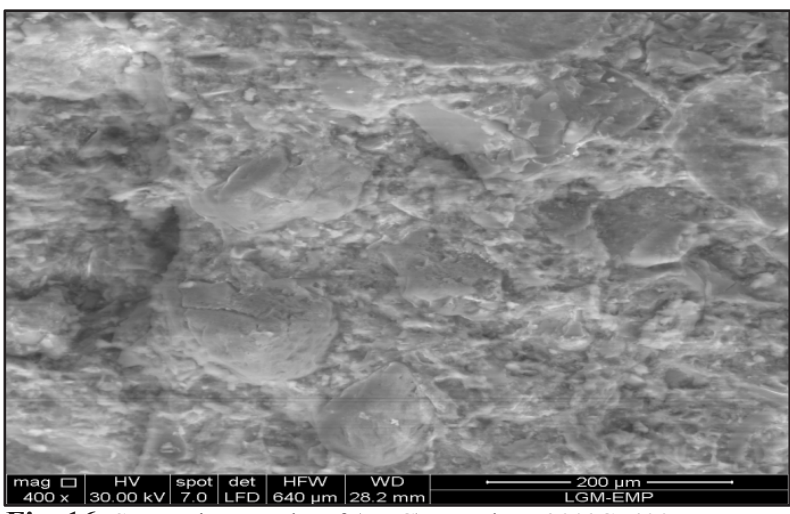

Fig. 16. SEM micrographs of (HPC) sample at $300^{\circ} \mathrm{C}, 400 \mathrm{x}$.

The microstructure of high performance concrete is denser and more compact (Fig.16). Homogeneity of the matrices is however significantly different.

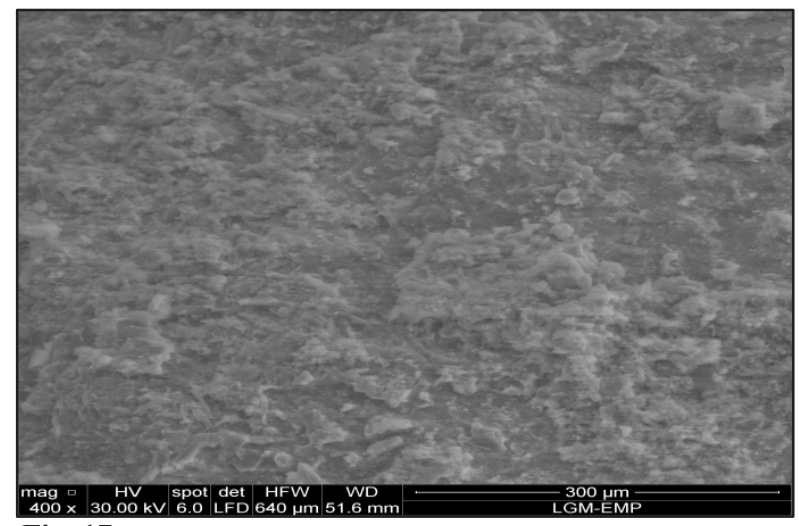

Fig. 17. SEM micrographs of $(\mathrm{OC})$ sample at $300^{\circ} \mathrm{C}, 400 \mathrm{x}$.

\subsubsection{At $600^{\circ} \mathrm{C}$}

Cracking is much more pronounced for heated samples (Fig.18) and (Fig.19), especially at $600{ }^{\circ}$ C. At these temperatures, cracks are observed at the dough aggregate interface as at $300^{\circ} \mathrm{C}$ but also within the dough and in the aggregates. 


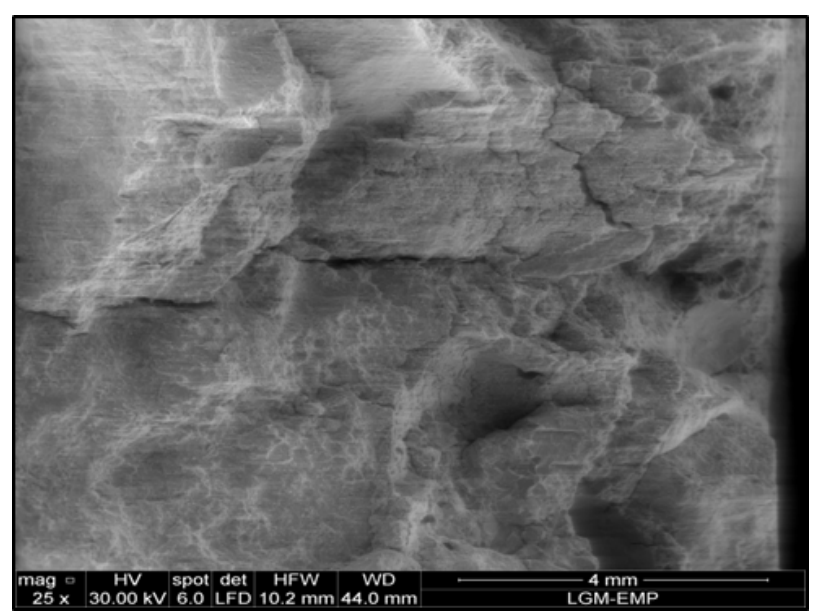

Fig. 18. SEM micrographs of (OC) sample at $600^{\circ} \mathrm{C}, 25 \mathrm{x}$.

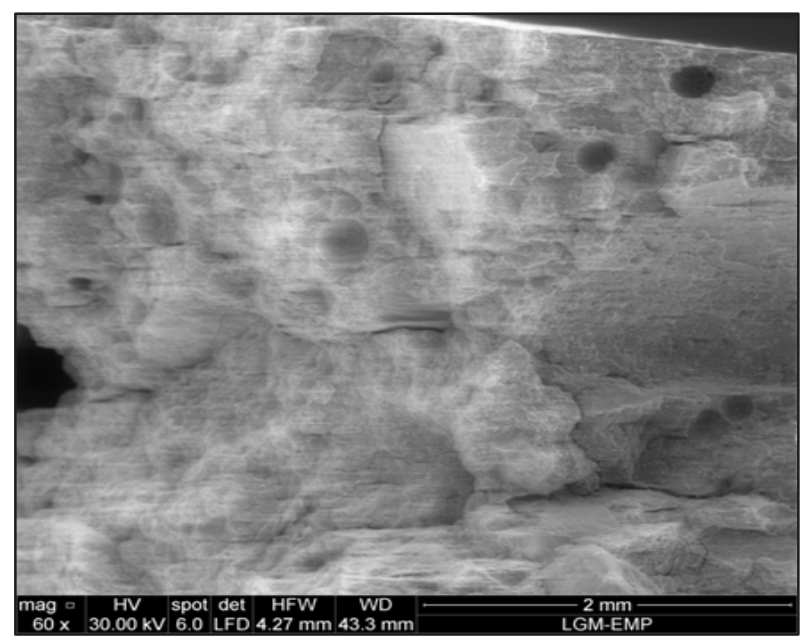

Fig. 19. SEM micrographs of (HPC) sample at $600^{\circ} \mathrm{C}, 60 \mathrm{x}$.

From the two previous figures (Fig.18) and (Fig.19), it can be seen that the crack density is much greater in the two types of concrete than that resulting from the previous temperatures.

For (HPC) These cracks are fine (of the order of 1 micron) (Fig.19), (Fig.21) and form a kind of cracking while they are wide (of the order of 10 microns ), cross the cement matrix (Fig.18), (Fig.20) and bypass the aggregates in ordinary concrete (BO). The origin of this behavior is not fully understood. Nevertheless, the authors, Noumowé et al [18] believe that the physicochemical transformations that take place during the heat treatment and after cooling and because of the porosity generated are at the origin of the formation of cracks.

The deterioration of the cement paste after heating to $600^{\circ} \mathrm{C}$ is evident. We can observe the cracks that leave perpendicularly from the surface of a siliceous granulate (Fig.22). Observing an increase in the number of pores and micro cracks from $300{ }^{\circ} \mathrm{C}$ on. At $600{ }^{\circ} \mathrm{C}$ the author [19] identified the presence of sintered areas, cracks, and small ettringite crystals, probably formed after the samples were cooled.

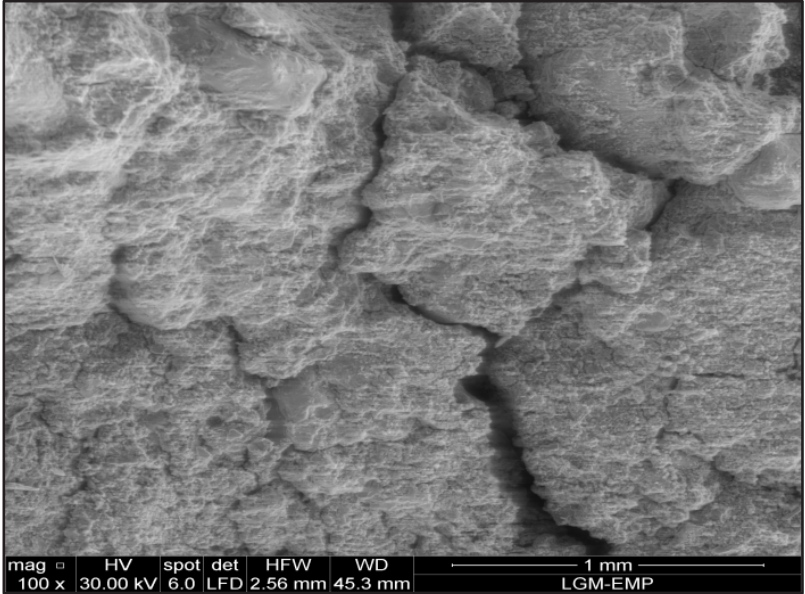

Fig. 20. SEM micrographs of $(\mathrm{OC})$ sample at $600^{\circ} \mathrm{C}, 100 \mathrm{x}$.

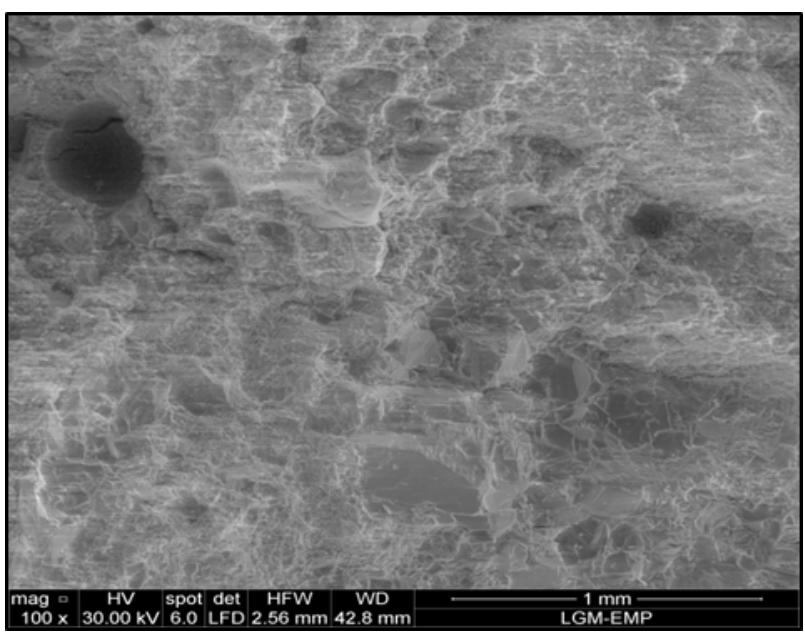

Fig. 21. SEM micrographs of (HPC) sample at $600^{\circ} \mathrm{C}, 100 \mathrm{x}$.

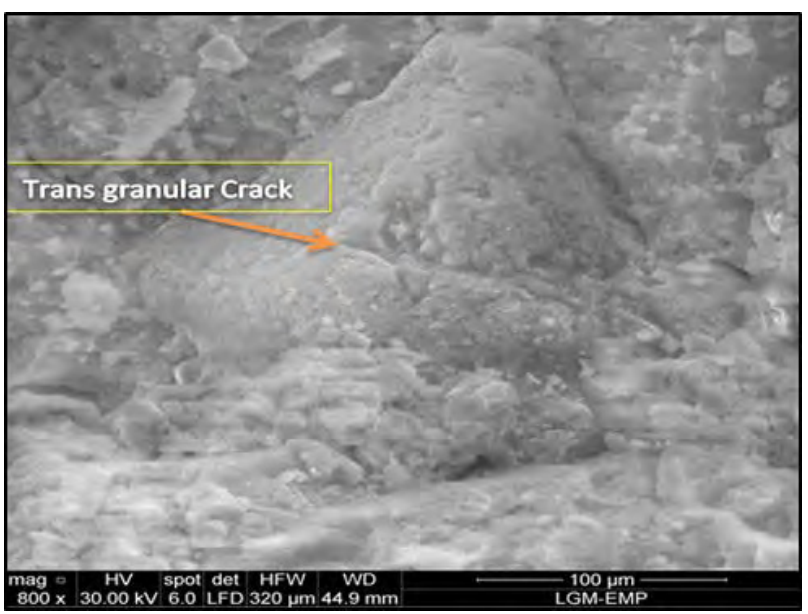

Fig. 22. SEM micrographs of (HPC) sample at $600^{\circ} \mathrm{C}, 800 \mathrm{x}$.

In addition, it is noted that the fracture surfaces of the samples, are intergranular in ordinary concretes (Fig.20), and are trans-granular in (HPC) (Fig.22). This can be explained by the fact that the cementitious matrix of the (OC) is less resistant because of weak bonds with the granulate which has a more permeable halo containing a large amount of $\mathrm{Ca}(\mathrm{OH}) 2$ portlandit, unlike that of the (HPC) containing mainly $\mathrm{CSH}$ which gives to concrete a very strong bond making the dough more rigid than the aggregate, and gives it a low capillary porosity which 
leads to good resistance to chemical attack or mechanical action.

\section{Conclusions}

Based on mechanical's tests and SEM examinations made on concrete specimens subjected to elevated temperature, the following conclusions can be drawn:

1. The residual compressive strength values of concrete mixture decreased significantly depending on increasing temperatures. The strength losses which were occurred in the concrete specimens increased when the temperatures reached $600^{\circ} \mathrm{C}$ and $900^{\circ} \mathrm{C}$ due to the decomposition of $\mathrm{C}-\mathrm{S}-\mathrm{H}$ gel.

2. The study led to a deeper understanding of the phenomena occurring in concrete when it is heated to a high temperature and to reveal differences in behavior between ordinary and high performance concrete. The fact of cooling the concrete in the open air, the latter undergoes a thermal shock seeing its mechanical properties drop in a very fast way which is of the order of $81 \%$ for the (OC) against $91 \%$ for the (HPC) compared to initial resistance.

3. Inclusion of $10 \% \mathrm{SF}$ into concrete (as a replacement of cement weight) significantly improved the compressive strength at $20^{\circ} \mathrm{C}$ and reduced it markedly with increasing temperature. The strength reduction starts from elevating temperature $450^{\circ} \mathrm{C}$ to $900^{\circ} \mathrm{C}$ with sharp drop which may be due to internal cracks formation as a result of volume expansion of concrete matrix.

4. The significant drop in mechanical and microstructural properties may be the consequence of phenomena occurring during the fast cooling method.

5. Temperature causes chemical changes in the hydration products, leading to the appearance of cracks, voids and intense paste shrinkage. These effects, added to the differential movement between the paste and aggregates, promote intense degradation of concrete properties.

6. According to results of SEM examination, the adherence of aggregate and cement paste decreased depending on increasing temperature. Therefore, the most of the cracks develop at the weak interface around the aggregate.

7. Based on our previous observations, it is concluded that high performance concrete may have cracks of different types. First, the trans-granular cracks that passes through aggregates, usually those of a quartz nature. It is possible that these cracks are due to the cleavage phenomenon that characterizes these aggregates. Second, the cracks surrounding the aggregates. These are mainly related to the gradients of dimensional variations between the cement matrix and the aggregates. In this temperature range, the aggregates expand as the matrix shrinks by dehydration.

8. The mode of cracking is bound the interface area pasteaggregate which is considered the weak point of the concrete. This zone of high porosity plays an important role and its composition depends strongly on the nature of granulate and the properties of the cement paste.

9. The effect of heating is more pronounced for ordinary concrete, namely an increase in porosity due mainly to a transformation of small pores in large pores, presumably by rupture of the partitions of the capillaries under the effect of the pressure of water vapor generated by increasing the temperature.

10. High performance concrete is more vulnerable than ordinary concrete at high temperature.

\section{References}

[1] M. Abramowicz, R. Kowalski, The influence of short time water cooling on the mechanical properties of concrete heated up to high temperature, Journal of civil engineering and management. Vol XI, N², pp. 85-90, (2005).

[2] CEN/TC, 250/SC2 N 0466 prEN 1992-1-2 (Draft for stage 49) Eurocode 2, Design of concrete structures- Part 1.2: General rules - Structural fire design, (2002).

[3] I. Hager, High temperature behavior of high performance concretes- evolution of the main mechanical properties, Doctorat thesis of the national school of bridges and highways, France, (2004).

[4] P. Pimienta, I. Hager, Fire behavior of high performance concrete with fibers, report HPC $\mathbf{2 0 0 0}$, (2003).

[5] SK. Hando, S. Agarwal, SK. Agarwal Physicochemical, mineralogical, and morphological characteristics of concrete exposed to elevated temperatures, Cem Concr Res , 32:1009-18, (2002).

[6] BM. Luccioni, MI. Figueroa, RF. Danesi, Thermomechanical model for concrete exposed to elevated temperatures, Eng Struct; 25:729-42.

[7] CP. Aitcin, High -performance concrete, modern concrete technology $\mathbf{5}$, University of Sherbrook, Canada, pp 216-220, (2001).

[8] RILEM TC129-MHT, Rilem Technical Committees 129-MHT - test methods for mechanical properties of concrete at high temperatures, part 1 : Introduction, part $2:$ Stress-strain relation, part 3 : Compressive strength for service and accident conditions. Materials and Structures, Vol. 28, , no $181: 410-414$ (1995).

[9] RILEM TC129-MHT, Test methodes for mechanical properties of concrete at high temperatures, Materials and structures, Vol.33, pp 219-223 (May 2000).

[10] H.Yang, Y. Lin, C.Hsiao, J-Y. Liu, Evaluating residual compressive strength of concrete at elevated temperatures using ultrasonic pulse velocity, Fire Safety J, 44:121-30, (2009).

[11] Ö.Arı̈̈z, Effects of elevated temperatures on properties of concrete, Fire Safety J, 42:516-22, (2007).

[12] H. Tanyıldızı, A. Cosßkun, Performance of light weight concrete with silica fume after high 
temperature, Constr Build Mater, 22:2124-9, (2008).

[13] M Talha Junaid, A. Khennane1, O. Kayali1, Investigation into the Effect of the Duration of Exposure on the Behaviour of GPC at Elevated Temperatures, MATEC Web of Conferences 11, University of New South Wales Australia, $5 p, \quad(2014)$

[14] Georgali B, Tsakiridis PE. Microstructure of firedamaged concrete. A casestudy. Cem Concr Compos, 27:255-9, (2005).

[15] Ö. Arıöz, Effects of elevated temperatures on properties of concrete. Fire Saf;42:516-22, (2007).

[16] N.Yüzer, Aköz F, Öztürk LD. Compressive strength-color change relation inmortars at high temperature. Cem Concr Res, 34:1803-7, (2004).

[17] G.Giaccio, R.Zerbino, Failure mechanism of concrete combined effects of coarse aggregates and strength level, Adv Cem Based Mater, 7:41-8, (1998).

[18] A.Noumowé, Effet de hautes températures (20$\left.600^{\circ} \mathrm{C}\right)$ sur le béton. Cas particulier du béton a hautes performances, Lyon, 233p Institut National des Sciences Appliquées de Lyon, (1995).

[19] M.Sousa. Estudo exnerimental do comnortamento mecânico e da microestrutura de um concreto convencional anós simulacão das condicões de incêndio. Belo Horizonte. Thesis (Master) Iniversidade Federal de Minas Gerais, 126 , (2009). 